The Version of Record of this manuscript has been published and is available in the International Journal of Computer-Supported Collaborative Learning

https://doi.org/10.1007/s11412-019-09295-1

\title{
IMAGINING WITH IMPROVISED REPRESENTATIONS IN CSCL ENVIRONMENTS
}

\author{
Rolf Steier \\ Magdalena Kersting \\ Kenneth Silseth \\ University of Oslo
}

\begin{abstract}
KEYWORDS
Imagination; Representation; Embodied Interaction; Maps; Computer-Supported Collaborative Learning; Multimodality
\end{abstract}

To cite this article: Steier, R., Kersting, M., \& Silseth, K. (2019). Imagining with improvised representations in CSCL environments. International Journal of Computer-Supported Collaborative Learning, 14(1), 109-136. 


\title{
IMAGINING WITH IMPROVISED REPRESENTATIONS IN CSCL ENVIRONMENTS
}

\begin{abstract}
This study contributes to our understanding of meaning making in CSCL environments by examining a specific aspect of collaborative problem solving in which students improvise, introduce, and make meaning with representations in disciplinary domains. These situations include the embodied and imaginative processes of discovering new representational possibilities and artifact meanings. Much of the research on student-generated representations examines situations in which students are asked by a teacher or researcher explicitly to produce representations. However, we need more knowledge about how students within CSCL settings introduce representations from outside of the designed environment or intended task in order to solve a problem. To unpack the processes of collaborative improvisation and meaning making, we take a sociocultural stance towards imagining. This stance involves considering the socially and materially situated ways that participants express new possibilities and alternative situations that extend beyond the present reality. Focusing on a specific task based on maps as disciplinary representations, we analyze video data of upper secondary physics students working in small groups in a co-located CSCL environment. To characterize shifts across boundaries of several modalities including the verbal and gestural, digital and physical, and two-dimensional and three-dimensional, we identify emergent representations as imaginative productions. The findings extend current research on collaborative meaning making by bringing attention to the processes through which improvised representations emerge. This knowledge is key to facilitating the discovery of representational possibilities in CSCL environments.
\end{abstract}

\section{KEYWORDS}

Imagination; Representation; Embodied Interaction; Maps; Computer-Supported Collaborative Learning; Multimodality 


\section{INTRODUCTION}

One of the fundamental themes of CSCL research involves exploring how small groups of students navigate multimodal constellations of representations and artifacts, yet we know little about the precise means through which improvised representations emerge in collaborative scientific discourse. The roles of different modes and multiple representations in student learning processes are particularly important as digital representations become more sophisticated and complex, and as new forms of computer-supported participation and collaboration are identified.

Prain and Waldrip (2006) draw a useful distinction between multiple and multimodal representations: Multiple representations encompass the practice of repeating and re-representing the same concept through different representational forms. Multimodal representations constitute the integration of different modes (e.g. spoken and written language, drawings, and gestures) within one representation or across several representations to construct a concept. Computers have been acknowledged for their potential to support student learning by linking multiple representations in ways that support broader conceptual understanding (White \& Pea, 2011). Moreover, digital learning environments (Tang, Tan, \& Yeo, 2011) and mobile learning (Nordby, Knain, \& Jonsdottir, 2017) provide settings where the interplay of modalities can be studied in a pure form. In CSCL environments, these kinds of arrangements might occur within an entirely online environment containing multiple modes of interacting (e.g. through a text chat and digital white board (ÇakIr, Zemel, \& Stahl, 2009)), or might involve face-to-face collaboration in a place containing physical and digital elements (e.g. using gesture and language over an interactive tabletop (Davidsen \& Ryberg, 2017; Evans, Feenstra, Ryon, \& McNeill, 2011)). In the latter case, referential shifts between digital and physical features of the setting are fundamental to the activity.

Often, it is the interaction with digital representations through dialogue and collaboration that gives particular insight into how students learn with multiple modalities. These kinds of collaborative sense-making processes with designed digital representations have received significant attention in CSCL (Çakir et al., 2009; Dwyer \& Suthers, 2006; Furberg, Kluge, \& Ludvigsen, 2013). However, the use of student-generated representations has received less attention than how students understand representations provided as a part of a CSCL environment (Prain \& Tytler, 2012). In one example from a CSCL setting for mathematics, Çakir et al. (2009) demonstrated that small groups of students in a multimodal workspace integrated 
drawings on a virtual white board with text-based interaction to maintain a continuous meaningmaking trajectory. In another study that focused on a face-to-face CSCL environment, Medina and Suthers (2013) showed how students using collaborative drawing software and table top resources for building electric circuits configure "the environment through multiple surfaces to mediate their meaning making" (p. 333).

These studies clearly suggest a growing interest in the processes through which students introduce and generate their own representations in the context of scientific problem solving. However, the majority of research on student-generated representations considers representations students are explicitly prompted to produce as part of a designed aspect of a classroom task (or CSCL environment). Much less attention has been paid to cases when, in order to solve a problem, students introduce unprompted representations by drawing on resources from outside the designed environment or task. We refer to such situations as involving improvised representations.

Improvised representations are in many ways similar to what Enyedy (2005) refers to as invented representations. In this important study, Enyedy traces the trajectory of an elementary school classroom working with maps as they (re)invent topographical lines as a means for expressing height on a two-dimensional map. Looking particularly at gesture in the context of the broader sociomaterial setting of a classroom, the study demonstrates "that the students and the teacher opportunistically assembled resources to understand and solve their collective problem" (Enyedy, 2005, p459). It is this spontaneous assembling of resources in a collaborative act of meaning making that characterizes both improvised and invented representations. However, there is an important difference: Though students adopt everyday resources in order to invent this new representation, the context of invented representations includes a lesson plan and a teacher guiding them to this invention. In contrast, we define improvised representations as developed by students as a means to solve another problem, not the result of a classroom activity that is intended to produce specific representational outcomes.

Research on the use and emergence of such improvised representations constitutes a significant gap in CSCL literature, and attending to the ways that students expand their local context to create new representational possibilities will give us a richer understanding of student problem solving and meaning-making practices. It is important to understand not only the collaborative learning processes in designed, controlled, or intended contexts, but also the 
unexpected ways that learners alter their activities and resources. Attending to this gap involves generating knowledge about the complexity of learning situations in which students are using and improvising representations when working on tasks that are digitally mediated, sometimes without the immediate presence of a teacher. Such learning situations involve students' use of imagination to reorganize their local environment in order to meet their particular problemsolving needs. Additionally, deepening our understanding of the cases when students work outside of the planned CSCL environment can contribute to the design of more effective tools and resources.

We define improvised representations as visual and material artifacts and embodied actions that may begin in everyday use and transition to disciplinary (scientific) practice. One particularly illustrative instance of the kind of phenomenon that we refer to is drawn from our dataset in this study. A pair of students, in attempting to depict the shortest path of an airplane traveling from Oslo to New York, brought out a wrapped sandwich from a backpack to stand in for a model of the earth. Holding the sandwich between them, the pair took turns tracing possible flight paths over the curved surface of the sandwich. Thus, through the improvisation of the students, one of the multitude of everyday objects that populate classrooms (i.e. lunch) developed meaning as a disciplinary representation in the form of a three-dimensional map. Students' everyday experiences and objects can function as mediational means for discussing disciplinary issues and solving tasks when engaging in academic matters (Silseth, 2018).

Research on collaborative learning with multiple representations has shown that students demonstrate significant creativity in their ability to navigate and shift between material and digital representations (White \& Pea, 2011). Groups of students make meaning by drawing on emergent and often unexpected representations. However, we have limited understanding about where these unexpected representations come from and how they develop. We take this observation as basis for our study that focuses on the emergent use of representations in the context of imaginative problem solving. We address the following research question:

How do small groups of students collaboratively improvise, introduce, and make meaning with representations that extend across multiple modalities?

We address these questions empirically by looking at how small groups of students use a web-based learning module with a map task that compares two- and three-dimensional spatial representations. As we will describe below, early observations of students revealed that this 
particular task seemed to invite students to introduce and improvise with new representations. In the following sections, we will first outline our theoretical approach to collaborative meaning making. We then introduce sociocultural approaches to imagining as an exploratory concept to account for the ways that new representational uses are discovered and to frame the ways students interpret this particular task. We then turn to a review of the disciplinary aspects of maps as representations with particular affordances, which in turn sets the stage for our study.

\section{MEANING MAKING AND REPRESENTATIONS IN CSCL ENVIRONMENTS} In this study, we adopt sociocultural theory as an overarching perspective on learning. This implies that learning is considered to be a socially- and environmentally-situated process of meaning making in which participants develop interpretations of activities and contexts together (Suthers, 2006; Vygotsky, 1978; Wertsch, 1993). For the purposes of this study, we focus on meaning making that occurs in small groups through face-to-face interaction in a CSCL setting. In contrast to individualist epistemologies which highlight knowledge as information structures which may be attributed to one member of the group, sociocultural approaches to meaning making emphasize the participation processes of group members as emergent meanings in the group as a whole (Gee \& Green, 1998; Greeno, 1997). Language and gesture are considered to be psychological tools that mediate interpretations of the context. Thus, a verbal utterance or explanatory gesture reflects the group meaning-making process as opposed to reflecting an individual's isolated cognition. Physical tools and material artifacts, including visual representations, also mediate these interpretations while simultaneously constituting aspects of the context (Duranti \& Goodwin, 1992; Van Oers, 1998; Enyedy, 2005). These artifacts are not containers of meaning but are rather embedded with meaning potentials through historical use and cultural practices (Wertsch, 1993). As one example relevant for this study, maps, as cultural and historical artifacts, mediate a variety of activities from navigation to design, and their use and meanings develop over long trajectories within and across these particular disciplines. Suthers (2006) emphasizes that these referential resources become embedded with meaning through processes of negotiation by participants. These negotiations include building on prior interpretations made relevant through language, gesture, or the manipulation of the representation. Suthers notes, 
In this manner, collaboratively constructed external representations facilitate subsequent negotiations; increasing the conceptual complexity that can be handled in group interactions and facilitating elaboration on previous conceptions. The expressive and indexical affordances of a medium will affect its value as a referential resource. (2006, p. 329)

In other words, a small group of collaborators needs to be able to perceive and communicate about the relevant features of a representation for it to be taken up as a meaning-making resource. Another implication of our use of sociocultural theory is that the status of a particular object's mediating function as a representation cannot be removed from its use in context. Zemel and Koschmann (2013) articulate this characteristic of representations by arguing that objects only become representations when their indexical properties become relevant in use:

Objects, be they drawings, gestures, graphs, texts, formulae, etc., are not themselves representations. We hold that representations are these objects and the way they are used in referential work. This makes representations referential resources used in the pursuit of interactional goals or outcomes that achieve their meaning through their referential use. In our view, no object is inherently representational in and of itself. (p. 67)

In this sense, representational qualities of an object emerge in situated practice. However, although we adopt this broader perspective on representations as practices (Greeno \& Hall, 1997), we are particularly interested in improvised representations as being adopted from outside of the intended activity; representations that are not provided by the teacher or designed into the learning resource. To characterize this distinction and to deepen our understanding of the phenomenon, we introduce a perspective built on sociocultural approaches to imagining.

\section{IMAGINING WITH REPRESENTATIONS}

One contribution that we wish to make through this study is the introduction of sociocultural perspectives on imagining into the CSCL field; this concept may in particular help us to understand the phenomenon of improvised representations. Imagining, from a sociocultural perspective, is an interactional process that involves the ways a group of participants interact with each other and the world to express possibilities and situations that are different from the present reality (Nishizaka, 2003; Murphy, 2004; Nemirovsky \& Ferrara, 2009; Zittoun \& 
Gillespie, 2015, Steier \& Kersting, in press). Imagining, like other sociocultural processes, develops through interaction between and among participants and their environment. Linking imagination to collaboration contrasts with a long tradition of studying imagination as the mental images of individuals (Nishizaka, 2003). Imagination includes seeing, creating, and communicating new ideas, and is thus required to see the representational qualities and possibilities of an object (Zittoun \& Gillespie, 2015). Imagination thus expands the representational possibilities of a designed CSCL setting. The context of being included in a textbook, in a lecture, or in a web resource can make the indexical properties of a particular (potential) representation explicit. That is, the representational relationship between an image and a concept or phenomena can be framed by the pedagogical situation. When objects exist outside of that situation, or are framed in a different way, learners use their imagination to recognize representational needs of a specific task and to develop new or unexpected meanings.

In line with previous research on imaginative processes in math and science, we regard imagining as distributed in ecologies of local materials and resources (Hutchins, 2010; Nemirovsky \& Ferrara, 2009). As proposed by Nemirovsky and Ferrara (2009), mathematical imagination "can illuminate the roles of tools and materials - not as 'embodiments' of mathematical ideas, but as means to productively extend the horizon of possibilities that students come to entertain" (p. 173). Imaginative activity thus involves working with the representational affordances of a given setting, and the flexibility to allow the expression and exploration of alternative situations that differ from that of the immediate "reality". Characterizing imagination as materially and physically situated implies that imagining depends on attention to features and resources of the local environment (Hutchins, 2010; Jornet \& Steier, 2015). In other words, a learner's ability to explore possibilities and to bring new ideas into the world depends to a great extent on the ways that aspects of the setting can be productively appropriated in order to depict these ideas.

Characterizing imagination as a social process means that a group of people may explore (imagined) possibilities through communicative processes. Alternate situations and abstract ideas may be co-created or considered by participants through the mutual elaboration of semiotic resources like language, artifacts, and bodily performances. Conceptualizing imagination as a social process suggests how important imagining may be in school situations such as small group work, teacher facilitated discussion, and the production of knowledge artifacts (Furberg, 2016; 
Furberg et al., 2013). This approach to imagining allows us to draw on findings from studies of collaborative learning, shared representations, communicative practices, and problem solving. Analytically this implies that researchers can study imaginative processes in small group settings by attending to the semiotic productions that participants develop to interact with alternative situations.

Finally, imagination is also an embodied process (Lakoff \& Johnson, 1999; Murphy, 2004; Nemirovsky \& Ferrara, 2009; Steier \& Kersting, in press). This may be viewed as an extension of the notion of imagining as not bounded by the brain of an individual. Imagination is considered embodied because it depends on the sensory experiences of one or more bodies interacting in the world, as well as on our bodies' functions as tools to think and communicate with. For example, in a recent study by Steier and Kersting (in press), upper secondary physics students trying to imagine the nature of gravity drew on a variety of bodily forms of knowing including past experiences of the feeling of gravitational forces on one's feet, on the imagined scenario of placing one's own body in outer space, and on the communicative properties of hand gestures to depict the trajectory of objects under the influence of gravity. Attending to these diverse embodied aspects of imagining is thus crucial for gaining a more complete understanding of productive imagining.

Studies of imagination have often been restricted to children's play and fantasy and to arts disciplines. Increasingly, however, disciplinary forms of imagining are recognized and developed. For example, in architecture (Murphy, 2004) and exhibition design (Jornet \& Steier, 2015), designers often engage in "embedded skits" as a strategy for acting out and performing the experience of being in a future space. These performances allow participants to consider the implications of design decisions in the present by collectively imagining their outcomes. Similarly, in the discipline of mathematics, mathematical imagination involves maintaining a collection of possible consequences for actions in the present (Nemirovsky \& Ferrara, 2009; Nemirovsky, Rasmussen, Sweeney, \& Wawro, 2012). Nemirovsky and Ferrara (2009) illustrate this process through the ways that students in an algebra class consider the possible triangles that might form by projecting a set of intersecting lines. Thus, mathematical symbols characterize possible outcomes instead of describing present situations.

Imagining is an important analytical lens for making sense of improvised representations for several reasons. First, the act of recognizing the representational needs of the task requires 
imagining that a potential resource might be useful in solving the task. Students recognize that their capacity to complete a task may be improved if they alter their current material environment and introduce a new representation. This recognition involves imagining other possibilities for exploring their current situation. Second, imagination is required to assign new meanings to improvised representations. Seeing a sandwich as representing the earth, or one's hand as a stand in for a map depends on imagining. Finally, exploring different possibilities with these improvised representations also requires imagining. For example, tracing a possible pathway over the imaginary map, or rotating the "basketball" earth to find a useful orientation are also best understood as ways to explore possibilities, and therefore as imaginative acts (Nemirovsky \& Ferrara, 2009). In the next section we discuss maps as a particular type of disciplinary representation.

\section{MAPS AND MAPPING AS LEARNING DOMAIN}

By compressing geographic structures to human scale, maps give us access to reality beyond our reach (Wood, 2010). In providing a small and simple model, maps are representation of the surface of the earth that can be used in place of the earth itself (Anderson \& Leinhardt, 2002). By representing spatial and temporal features of the world, maps reorganize space in ways that allows us to establish a geometric correspondence between our reality and a map (Downs \& Liben, 1991).

As long as there have been maps, however, cartographers and mathematicians have grappled with the impossibility of portraying the earth in two dimensions (Snyder, 1993). There are two distinct challenges: first, the surface of the earth is curved. Converting a curved surface to a planar one necessitates "stretching" and "squashing" of some areas of the original surface (Brainerd \& Pang, 2001). Second, in moving between maps and the world, we have to translate between dimensions. The world is three-dimensional and we think of the surface of the earth as embedded in three-dimensional space. Yet, maps are essentially two-dimensional representations. Map projections, therefore, always involve distortions because of tensions between curvature and flatness and between two and three dimensions..

The representational challenges of reading maps and dealing with cartographic distortions requires skills from disciplines including geography, math, astronomy, and physics (Snyder, 1993). Focusing on the learning domains of geography and astronomy, we will first shed light 
onto the distinct challenges of curvature and dimensionality respectively. Having done this groundwork, we will transcend disciplinary boundaries to characterize general abilities to read and navigate maps.

The geography literature on learners' challenges when working with maps is rich (Battersby \& Kessler, 2012; Bausmith \& Leinhardt, 1998; Wiegand, 1999). General findings suggest that students are not competent map users (Bednarz, Acheson, \& Bednarz, 2006). Many students lack deeper conceptual knowledge of how maps represent reality by introducing distortions (Anderson \& Leinhardt, 2002). Tyner (1987) went so far as to call the distorted conception of the earth caused by the common Mercator map the "Mercator mentality". Indeed, reading maps entails an inherent complexity due to the multiple relations between the map and the curved surface of the earth (Anderson \& Leinhardt, 2002). Novices have more difficulty in moving back and forth between cartographic representations and the real-world objects represented. Anderson and Leinhardt (2002) suggest that what distinguishes an expert geographer from a novice is the use of a map as a tool for reasoning as opposed to reasoning with and within the map itself.

While geographers focus on the challenges of distortion, astronomers foreground the problem of dimensionality. Indeed, astronomy as a fundamentally three-dimensional discipline poses special demands on learners because the field involves extreme distances, translations, and the motion of objects in a three-dimensional universe (Barab, Hay, Barnett, \& Keating, 2000). Astronomy educators, thus, interpret spatial thinking in terms of being able to extrapolate threedimensionality from two-dimensional representations (Eriksson, 2014; Eriksson, Linder, Airey, \& Redfors, 2014). They subsume the skill of "reading the sky" under a more general spatial ability (Eriksson, 2014). This ability allows learners to understand and elaborate on a threedimensional body in terms of two-dimensional geometrical representations (Latour, 1986). Being able to extrapolate from two-dimensional representations to a three-dimensional reality can be hard for learners because of difficulties in understanding the multidimensionality of the Universe (Eriksson et al., 2014). Students struggle in particular when the spatial and temporal scales are extremely large and thus inaccessible to direct perception (Eriksson et al., 2014).

While most accounts of the representational challenges of maps are situated in the disciplinary discourse of a particular field, it is clear that the ability to read maps requires skills that transcend disciplinary boundaries. What is common to all disciplines is the understanding 
that navigating maps is a cognitively complex task. Maps reorganize space in ways that can contradict learner's experiences (Taylor \& Hall, 2013). Yet, mastering these cognitive tasks has become increasingly important in light of the rise of geospatial technologies. Digital map services such as GoogleMaps ${ }^{\mathrm{TM}}$ have become a ubiquitous feature of daily life in the $21^{\text {st }}$ century. Indeed, digital maps and the logic of space informed by them guide the daily lives of students. As a consequence, there is a change in how we think with maps and what counts as cartographic knowledge (Silvis et al., 2018).

By acknowledging the increasingly dynamic and multi-faceted nature of map navigation (Farmann, 2010), researchers have introduced interactive digital mapping to support a new form of digital literacy (Silvis et al., 2018). Digital mapping adds a dynamic facet to traditional paper maps when students develop spatial understanding of places (Silvis et al., 2018). Such learning processes often unfold through interaction. Silvis et al. (2018), for example, studied collaborative cartographic experiences in which learners used a computer screen and GoogleMaps ${ }^{\mathrm{TM}}$ as the repository and reference for their gestures. Likewise, Eriksson et al. (2014) call for computer simulations and hands-on experiences to facilitate the ability to extrapolate three-dimensionality. With the exception of these initial explorations, however, interactive digital maps have yet to receive much attention in the CSCL literature.

It is against the backdrop of interactive digital mapping that we situate our study. To be able to answer our research question, it is important to characterize collaborative learning processes that are framed by shifts between digital and physical representations. In particular, such a characterization is useful if students introduce and improvise representations that extend across multiple modalities.

\section{PROJECT BACKGROUND AND TASK}

Data for this study were collected through a larger design-based research project called ReleQuant, which investigates new ways of teaching modern physics concepts through webbased learning modules on the topics of general relativity and quantum physics (Bungum, Henriksen, Angell, Tellefsen, \& Bøe, 2015; Henriksen et al., 2014). The project takes a sociocultural stance on learning science (Vygotsky, 1962) with a particular focus on facilitating understanding through "talking physics" (Henriksen \& Angell, 2010; Lemke, 1990). This focus is reflected in the design of the modules: several tasks invite final year upper secondary school 
students to discuss in pairs, small groups, or in plenum. Additionally, the design of the module activities is intentionally multimodal, asking students to write short text responses and perform simple drawing tasks, as well as record short verbal dialogues about the content matter.

This study considers part of the first two design and development cycles of the general relativity module. The module is divided into a sequence of three chapters, which constitute two 90-minute classroom periods. The last chapter in the general relativity module presented the core concept of general relativity: gravity is curvature of spacetime (for a detailed look at student understanding of this concept, see Kersting \& Steier, 2018). In a series of activities, students explored the geometry of curved spaces by collaboratively working with interactive digital maps and spacetime diagrams. The first task in this series asked students to consider and discuss in small groups why the flight path of a plane traveling from Oslo to New York appears to be a curved line when viewed on an ordinary world map (Figure 1). For this study, we focused on this single discussion task because early observations revealed that the task seemed to be very engaging for students inviting them to introduce and improvise with new representations.

The purpose of the task was to introduce some of the challenges that arise when moving between two-dimensional and three-dimensional representations of curvature. In particular, students should become familiar with representational distortions. This task was followed by the introduction of time as a $4^{\text {th }}$ dimension and gravity as a manifestation of curved four-dimensional spacetime. It is worth noting that the task of finding the shortest path between two points on a world map is not a trivial one. Anderson and Leinhardt (2002) found that a flat map invites map readers to use their knowledge of flat geometry; geography undergraduate students and preservice teachers would often carry the mathematical rule that the shortest distance between two points is a straight line over to the geometry of world maps. 


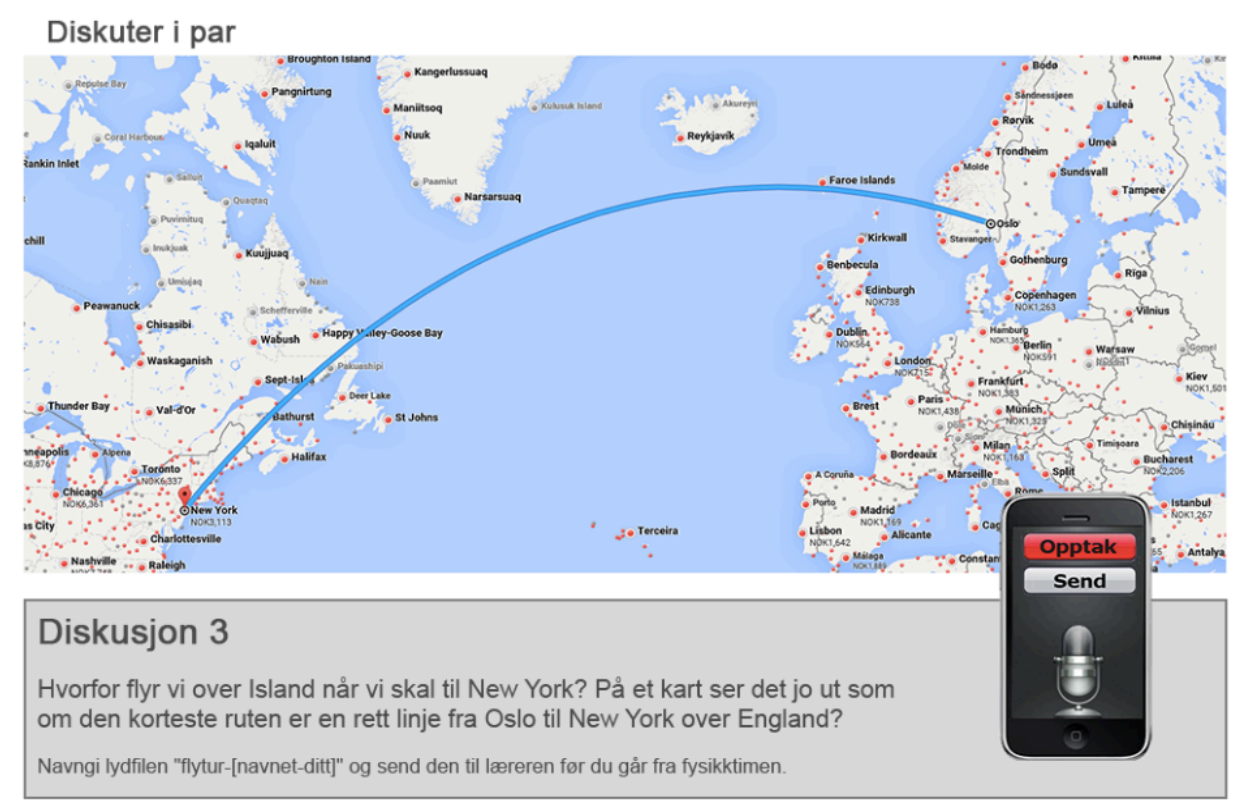

Figure 1 - The airplane task in the first version of the general relativity module: A world map presents the curved flight path between Oslo and New York and asks students: "Why do we fly over Iceland when we travel to New York?"

\section{DATA COLLECTION AND METHODS}

We collected video data of 15 groups of students from seven final-year physics classrooms in five Norwegian upper secondary schools over a period of two years. The students were organized in small groups (each group consisted of two, three, or four students), and the groups were placed at desks with one laptop per group or in some cases with individual laptops. The classroom organization depended largely on how the teachers chose to implement these modules. Teachers devoted three hours of class time for this particular module with two units of 90 minutes each. Video data enables us to study in detail how students make meaning in situ and how they collaboratively manage the task at hand (Derry et al., 2010). Because video data capture students' utterances, gaze and gestures, it also enables us to say something detailed and systematically about what types of representations students orient towards when engaging with the map task across the different groups, and how they engage with these representations.

When reviewing the total corpus of data of the 15 groups we identified segments where groups were working with this map task. The map task lasted for between 1 and 12 minutes depending in part on how the teacher organized the activity and how engaging the task was for the students. The segments were first transcribed, translated from Norwegian, and then viewed multiple times noting the representations used, the use of gesture, and the gaze of the 
participants. Sequences in which new or unusual representations were introduced were noted for closer analysis.

An important distinction we wish to draw is between provided representations and improvised representations. Whereas provided representations include visualizations within the web-based learning module, improvised representations include other productions that the students introduce or produce. If the students leave the web-module to search for other visualizations on the web, then we consider these to be improvised because they were not provided by the designed activity and CSCL environment. In this study we focus on such improvised representations in small group work.

Our analysis is inspired by principles as outlined by Interaction Analysis and Embodied Interaction (Jordan \& Henderson, 1995; Streeck, Goodwin, \& LeBaron, 2011). The importance of analyzing learning and meaning making on a microlevel has been emphasized within the CSCL community (Furberg, 2016; Krange \& Ludvigsen, 2008; Silseth, 2012). This approach emphasizes the need for analyzing meaning making and learning as sequentially organized and as an interactional achievement. The analytical focus is on how participants produce and respond to each other's utterances turn-by-turn when collaboratively engaging in an activity, and how the participants orient to resources that are made available in the context of interaction (Ludvigsen, 2012; Silseth, 2018). Furthermore, gaze and gesture become part of the meaning-making processes, and contribute to co-construction of knowledge and meaning. In analyzing these aspects, we distinguish between depictive gestures and indexical/deictic gestures (McNeill, 1992; Streeck, 2009). Depictive gestures involve using the hands to produce pictorial representations of some external referent (Streeck, 2009). For the purposes of this study, we characterize such productions as a type of (bodily) representation similar to other improvised representations because in interaction, attention is directed towards the visual/bodily aspects of the gesture itself. Indexical or deictic gestures such as pointing, on the other hand, are not considered to be improvised representations because they direct attention, not to themselves, but to some other feature of the world.

The transcript convention that we employ is based on Jefferson (2004) (see Appendix). Because gesture is central to our analysis, we also include detailed illustrations and images of bodily positioning and gesture taken from screen shots of the video material. To connect the moments of the verbal transcript with the corresponding gesture, we also adopt a notation in 
which a "•" symbol in the transcript corresponds with the moment from the video data of the associated gesture (Streeck, 2009). Because images are static and bodily movement and video data are continuous, we have made choices about the moments in time that best capture the movements relevant for our analysis. We view such transcription work as an important phase of analysis with embodied interaction (Davidsen \& Ryberg, 2017; Steier, Pierroux, \& Krange, 2015). Accordingly, we have emphasized gestural depictions to highlight the mutual elaboration of these gestures as shared representations.

\section{RESULTS}

During the initial classroom observation period, it quickly became clear that the map task invited the use of improvised representations. Reviewing the video data of the 15 groups, we noted the use of a variety of such representations including student drawings, basketballs, a sandwich, a tape measure, and GoogleEarth ${ }^{\mathrm{TM}}$. We identified six groups as improvising such representations. We additionally observed that students gestured extensively while engaged in this task.. Focusing only on depictive gesturing (not just pointing), we noted that nine groups incorporated gestural depiction into their discussions. This use of gesture and external representations were in addition to the use of the designed module by the groups.

Before narrowing our focus to one particular group of students whose conversation illustrates how improvised representations emerged within the collaborative meaning-making processes of several groups, we would like to give a more general account of our findings. When looking at the moments that preceded the introduction of new representations, we noted that students engaged in activities that blurred the boundary between digital and material representations. In addition to discussing and interacting with digital maps displayed on the laptop screen, students actively made use of the material properties of the screen by, for example, physically tracing or measuring digital images to find the shortest distance in a map.

More generally, we observed a high frequency of shifts across modalities. In addition to shifting between physical and digital representations, students frequently shifted between twoand three-dimensional representations while simultaneously moving between gestural and verbal modes of communication. This engagement in various strategies allowed students to fluidly shift between bodily, material, and digital representations and seemed to have helped the groups to both understand and overcome representational challenges of the given task. Specifically, we 
explored patterns in which several groups progressed from bodily to material forms of representations as they collaboratively developed more sophisticated means of dealing with the task. Often, students began using gestures and language as their primary tools of expression before turning to their local environment to identify possible "earths".

A common thread running through all of these meaning-making practices was the role of imagination in facilitating the discovery of representational possibilities and new artifact meanings. Here, imagination took a dual role: First, imagination allowed students to transcend their experience of space around them to entertain situations that differ from the present - such as following the route of a transatlantic flight between Oslo and New York. Second, imagination helped students to identify the representational affordances of their current environment to see new possibilities in the present - such as seeing the hand as the round earth or a flat map.

In the analysis below, we present the entire trajectory of one group working with this task. This group consisted of two students, here called Gunnar and Janne. This group sat at the front of the classroom on opposite sides of their table using a shared laptop. Gunnar and Janne spent seven minutes on this task, and we will present the analysis in three sequences. This group's trajectory demonstrated several patterns common among other groups including the extensive use of improvised representations and challenges in linking a verbally expressed understanding of the difference between two- and three-dimensional maps with the production of a visual demonstration of this relationship.

The rationale for presenting a trajectory and selecting the trajectory of this particular group is based on several considerations. First, focusing on trajectories enables the researcher to demonstrate "how multiple actions and people collectively produce phenomena" (Derry et al., 2010 , p. 22). Choosing to analyze a trajectory of one group, rather than a collection of episodes from different groups, allowed us to analyze in detail how the actions of the group develop over time as a collaborative activity (Mercer, 2008). A second consideration is about interactional transparency. That is, the group members' verbal and gestural contributions are characterized by a high degree of explicitness (Linell, 2009; Mercer, 2004). In this context, explicitness refers to the fact that the group's interaction provided us with a clear lens to examine representational practices. Third, this group introduced digital representations from outside the activity, including as GoogleEarth ${ }^{\mathrm{TM}}$. Focusing on this particular group enables us to shed light on the complex relationship between digital representations in and outside the task, with specific reference to 
representations used by many in everyday settings. Finally, the quality of the video data allows for clear viewing of both the face-to-face interactional aspects of the episode and the images on the computer screen.

\section{The task as a representational challenge}

In the first sequence, we observe how the map task presents itself as an educational challenge for Gunnar and Janne. The group interprets and formulates a brief answer to the main question in the map task ("explain the shape of the path") and then begins to introduce new gestural representations in an attempt to provide a justification for their answer. In this sequence, the analytical focus is on the mutual elaboration of the gestural representations and corresponding language, as well as the frequent references to the map representation provided in the CSCL environment. Additionally, we will see imagination play an important role for the participants in quickly adopting improvised representations as their referents (e.g. imagining a hand as a map). The sequence begins as Gunnar is reading the task out loud, as displayed in Excerpt 1.

\section{Excerpt 1}

\begin{tabular}{|l|l|l|l}
\hline 1 & Gunnar & $\begin{array}{l}\text { Why do we fly over Iceland } \\
\text { when we travel to } \mathrm{New} \text { York? }\end{array}$ \\
\hline 2 & Janne & $\begin{array}{l}\text { Becau: :se the earth is } \\
\text { round? }(0.2) \text { and } \bullet \text { this is } \\
\text { the shortest way. }\end{array}$ \\
\hline 3 & Gunnar & $\begin{array}{l}\text { Yes becau: :se }(0.4) \cdot \text { yes } \\
\text { because it's } \\
\text { [like m: : }\end{array}$ \\
\hline
\end{tabular}




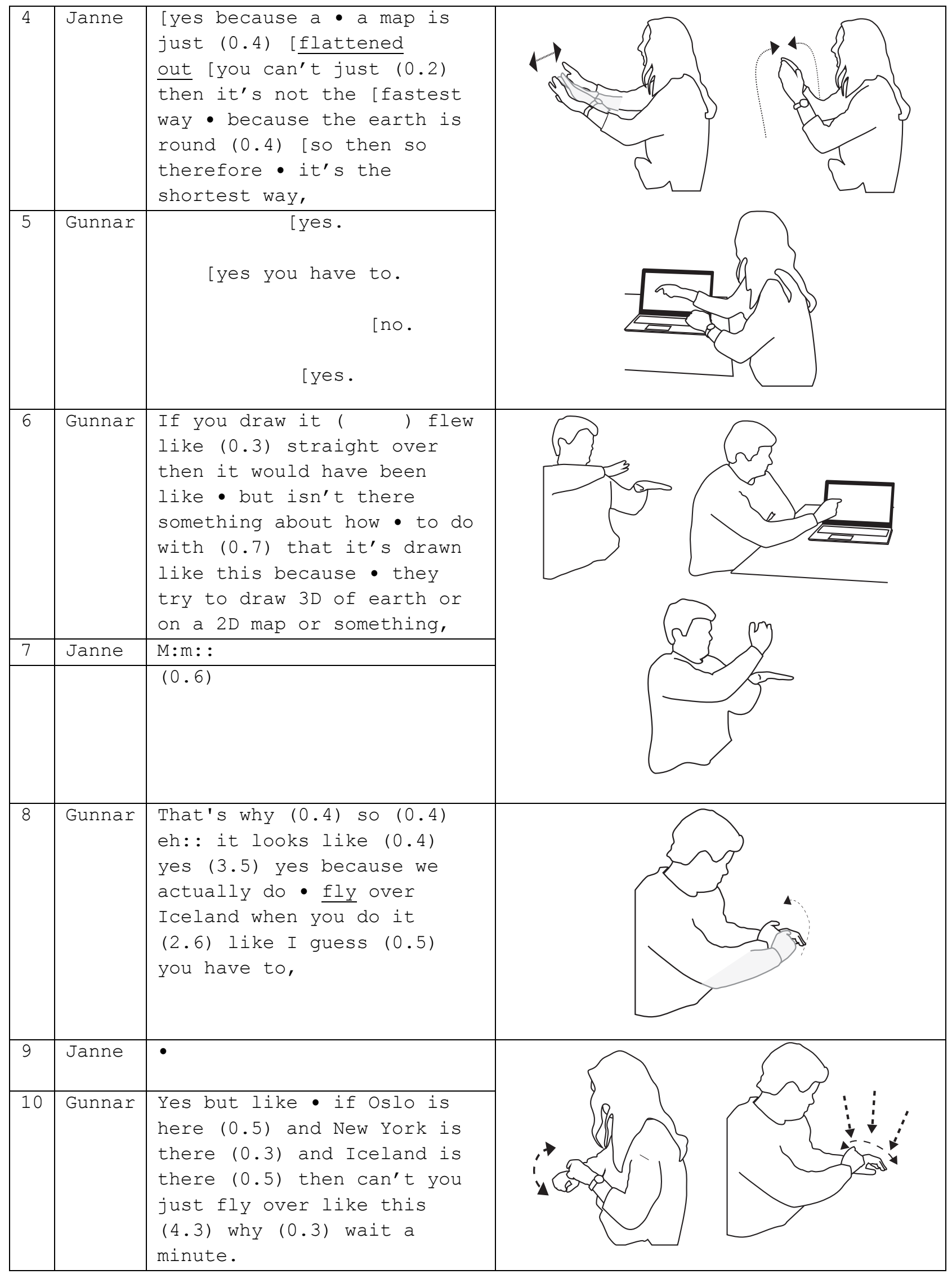




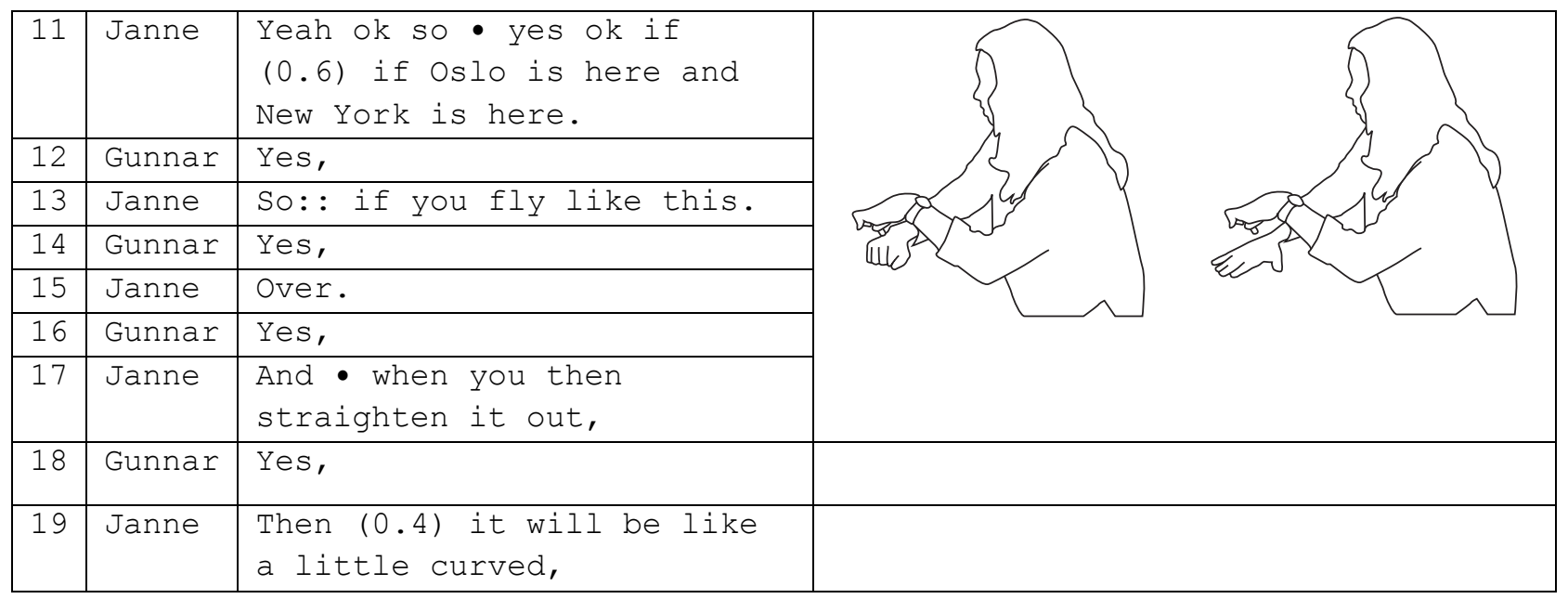

The episode starts with Gunnar reading the task out loud "Why do we fly over Iceland when we travel to New York ?" and Janne immediately responds that "Because the earth is round and this is the shortest way" as she traces the flight path over the screen (turn 2). Gunnar agrees, but then pauses while lifting both hands in the air to apparently depict the surface of the earth (turn 3). The use of "because" sets the stage for providing justification for Janne's answer, either because he wishes to clarify Janne's response, or perhaps because he recognizes that part of the task is to provide justification for one's answers. Janne then elaborates that a map is flat and the earth is round while she uses her hands to depict the flat map and then the round earth respectively (turn 4). This is the first time that she acknowledges the tension between flat and curved spaces. In recognizing flatness as a feature of a map representation, she articulates one important challenge of working with such a representation.

Next, Gunnar contributes to positioning their reasoning as a representational challenge by introducing the hypothetical situation of drawing the flight path (turn 6). As he raises the key distinction between a two-dimensional map and a three-dimensional earth, he shifts between pointing to the map on the screen and a two-handed gestural depiction of the round earth. Thus, in a short turn of utterances, the two students have identified both the challenges of dimensionality and of curvature.

Then, in turn 8, Gunnar initiates a key sequence of gestural elaboration. Gunnar places his left hand in a curved half-sphere shape down on the table as a stand-in for the earth. Using his right index finger, he slowly traces a possible trajectory of the flight path. As he questions "I guess?" he turns to Janne who reproduces the same depictive gesture so that both are now 
attending to their own hands simultaneously (turn 9). Thus, quite quickly the group has accepted that they are imagining a curved hand as the earth, but also using their other hand to imagine possible flight paths. Gunnar then elaborates on this gesturally constructed model by pointing to an imaginary Oslo and New York and illustrating the path between them (turn 10). In a few moves, one hand has become an earth marked by the location of cities while the other shows possible connecting routes of airplanes. Then, Janne (turn 11) moves her depiction into the table space between the pair while confirming Gunnar's proposition of indicating the locations of the two cities before connecting the path between them. This movement to the center of the table clearly marks this mutually constructed gesture as a shared representation. This move also coincides with a shift from a more exploratory use of the gesture to a more explanatory way of talking to Gunnar. In turn 17, Janne adds an additional aspect to this depiction by flattening her "earth" hand onto the table and tracing a new "bowed" path (turn 19). This move re-introduces the dimensional challenge of moving from three to two dimensions.

We wish to highlight a few key aspects of this sequence. First, the group immediately generates a verbal answer to the question, but it seems that to move on they need to either elaborate on this answer, to visualize it, or to justify the response representationally to each other. This need for representational justification can also be framed as an imaginative challenge. The group has quickly recognized that they must turn to their local environment in order to collectively imagine the conditions for this flight path. We also wish to note that the key representations emerging in this sequence include the map displayed on the screen from the module and a sequence of depictive gestures. Importantly, the pair shifts back and forth between these two different representational spaces, the digital screen and the shared (physical) gesture space (McNeill, 1992). The pair's verbal references to the representational challenges of maps (i.e. that a two-dimensional object represents three-dimensional space) are accompanied by frequent shifts between representational gestures in three-dimensional space, and indexing gestural references to the two-dimensional map on the screen. Finally, this sequence clearly illustrates imagination as an interactional achievement. The pair introduces and mutually elaborates on new depictive gesture to facilitate their intersubjective meaning-making process. Gunnar first introduces a particular way (curved hand down on the table) of depicting the problem space, which then gets taken up and elaborated on by Janne as she uses the same gesture to shift between the three-dimensional earth and the flattened two-dimensional map. The initial 
proposition of imagining one hand as the earth to solve the problem becomes a sequence of collective imagining as layers of meaning are added and alternative possibilities are explored.

\section{Struggling to become fluent in shifting representations}

As the episode continues, Janne and Gunnar begin to elaborate on the consequences of using flat maps as representations of three-dimensional earths, and how that shift is accomplished. We will see that their gestural depictions become more sophisticated in order to imagine these possible shifts, and that they are less reliant on the map from the computer screen. At the same time, they display struggles in resolving the task as they confront the limitations of their developing representations. We enter back into the episode in the next sequence, displayed in Excerpt 2, as the group expresses difficulty in articulating the shift between three and two dimensions.

\section{Excerpt 2}

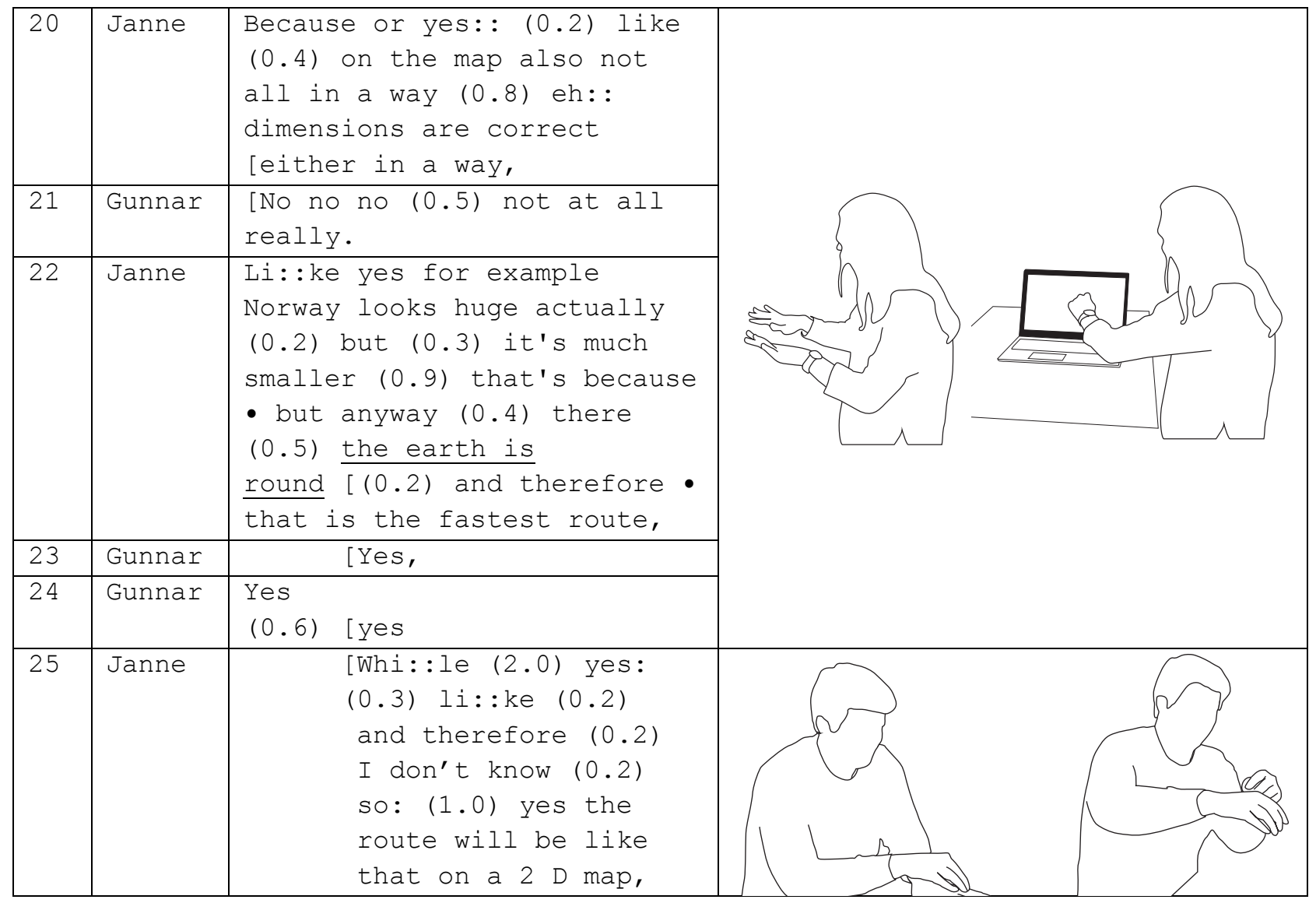




\begin{tabular}{|c|c|c|c|}
\hline 26 & Gunnar & $\begin{array}{l}{ }^{\circ} \text { Yes }{ }^{\circ}(0.5) \text { but I try to } \\
\text { think of how }(0.4) \text { cause it } \\
\text { you think • ok now we have a } \\
2 \text { D map (0.4) then we can't } \\
\text { you can't see }(0.2) \text { if we } \\
\text { draw the route like this } \\
(0.7) \text { on a } 2 \mathrm{D} \text { map ( } 1.8) \\
\text { the:n you don't see the } \\
\text { difference then it looks } \\
\text { like then the route is } \\
\text { actually longer (0.5) cause } \\
\text { you - have like a curve here } \\
(0.7) \text { and I guess the curve } \\
\text { will be longer than a } \\
\text { straight line like this, }\end{array}$ & \\
\hline 27 & Janne & $\mathrm{M}: \mathrm{m}[::$ & \\
\hline 28 & Gunnar & $\begin{array}{l}\text { [So I don't know if you } \\
\text { in a wa: :y [ }(0.5) \text { that } \\
\text { they that you } \bullet \text { rotate } \\
\text { like this to show the } \\
\text { entire route }(0.3) \text { or } \\
\text { the entire length of } \\
\text { the route, }\end{array}$ & \\
\hline 29 & Janne & $\begin{array}{r}{[\text { Yeah: yeah: }} \\
\text { yeah: yeah: }\end{array}$ & \\
\hline 30 & Janne & Yes maybe so. & \\
\hline 31 & Gunnar & $\begin{array}{l}\text { Ok cause it's the only thing } \\
\text { that makes sense }(0.3) \text { for } \\
\text { me 'that I don't know (0.7) } \\
\text { ( ) no ( } 0.4) \text { but ok it's } \\
\text { the fastest route. }\end{array}$ & \\
\hline 32 & & $\begin{array}{l}(23.7) \text { ((the group stops } \\
\text { recording their discussion } \\
\text { and they talk about what } \\
\text { they should name the audio } \\
\text { file)) }\end{array}$ & \\
\hline 33 & Janne & $\begin{array}{l}\text { But (0.6) ok if you }(0.2) \text { if } \\
\text { you } \cdot \text { have a ball like this } \\
\text { and (6.5) - like (1.7) eh: } \\
(0.6) \text { how - will it be if } \\
\text { you drive that trip then } \\
\text { (3.3) ((traces straight line } \\
\text { on screen)) will it be } \\
\text { longer? }\end{array}$ & \\
\hline 34 & Gunnar & $\begin{array}{l}\text { ((laughs) ) Drive through the } \\
\text { earth (0.5) eh: : }\end{array}$ & \\
\hline 35 & Janne & We should have had a Globe? & \\
\hline 36 & Gunnar & Visualized it, & \\
\hline 37 & Janne & Yes. & \\
\hline
\end{tabular}


This sequence begins with Janne describing some of the challenges of shifting between three and two dimensions and the inevitable distortions that such a shift entails. In turn 22, she states that Norway appears to be much larger on a flat map which suggests that she is aware of the relevance of the issue of distortion in map projections. However, rather than completing this argument by relating the distortion to curvature, Janne returns to her initial response that "the earth is round, so it's the fastest route". Gunnar laughs, acknowledging the difficulty in articulating their perspective, as Janne confirms that the flight path on the screen is correct "on a 2D map" (turn 25).

In turn 26, Gunnar builds once again on the same gesture from the previous sequence, here using two hands on top of each other to show the relationship between two and three dimensions. With his right hand depicting a round earth on top of his left hand depicting a flat map, he attempts to express the conceptual shift by exploring different possibilities of projecting three dimensions onto two. First, he flattens his curved right hand onto his left to visualize how a path on his curved hand corresponds to a path on his flat hand. Both students have used this gesture before and Gunnar repeats it in what seems as a stepping stone for him to introduce a new representational shift of dimensions.

By tilting and rotating his earth hand to form a projected curved path on top of his flattened 'map hand', he chooses a tilting movement to project a curved path onto a flat space (turn 28). This rotation involves a new strategy for depicting the dimensional shift. Gunnar wonders about the length of the curved line and flatting out his hand does not seem to give him a satisfactory answer. In tilting his curved hand towards the flat surface of his other hand, he explores a possibility of projecting dimensions that does not distort the length of the arc of his hand. Constructing a map projection always involves a choice of what properties of threedimensional space one wants to preserve e.g. area, direction, shortest distance. Moving between different representations of the dimensional shift, Gunnar grapples with the difficulty of finding a presentation that works for him in the setup of the task.

Thus, with the same initial depiction of imagining one's hand to be the earth, Gunnar and Janne present multiple ways of expressing the dimensional shift. From the perspective of imagination, this tilting strategy involves imagining the rotation of a surface onto a flat plane to imagine the projected flight path. This use of projection resembles imaginative processes 
described by Nemirovsky \& Ferrara (2009) in which mathematics students imagine the shape of triangles through laser projections.

In turn 31, after having performed this rotation several times, Gunnar acknowledges that this representation makes the most sense for him, but that this explanation is perhaps not sufficient as he states "I do not know" and repeats the initial verbal answer once more that "it's the fastest route". At this point, Gunnar attempts to bring the task to a close as he hits the stop recording button on his phone. Again, part of the task was to record their own discussion.

However, though the pair has completed the task, Janne re-opens the discussion in turn 33 by introducing a two-handed "ball". She continues by returning to the previous gesture of a curved earth-hand sitting on top of a flat map-hand. In an important turn, Janne reverses the task by asking what a straight-line path on the two-dimensional map would look like on a threedimensional model of the earth (turn 33). Here she traces a straight-line path between the two points on the computer screen while asking if translating this path onto a three-dimensional earth would result in a rounded path. This turn can be viewed as an imaginative problem-solving strategy. Here, Janne shifts between the two problem spaces and approaches the task of the shortest path from the opposite site. Instead of looking at the shortest path in three dimensions and the way its two-dimensional representation is distorted on a map, she starts from the shortest (straight) path on the two-dimensional map and tries to imagine what this path would look like in a three-dimensional setting. Posing the reversed question can be understood as a thought experiment or an imaginative strategy to resolve the initial task by entertaining alternate scenarios.

Gunnar jokes that that question would resolve in a straight path through the earth instead of along its surface which suggests a lack of consensus on what Janne was attempting to achieve with the proposed thought experiment. Importantly, in turn 35, Janne suggests that a globe would help them to visualize these paths while she turns and looks around the room. This suggestion demonstrates awareness of new representational requirements of the situation.

In this sequence, the students alternate quickly between dealing with the two challenges of maps: dimension and distortion. They demonstrate awareness of the relevant issues and explain them in more detail. However, their strategy of applying rotational projection and flattening to their gestural model does not resolve the task. The struggle to become fluent in these shifting representations is highlighted by frequently returning to their initial verbal 
response. The gestural depiction initiated in the first sequence continues to develop through a mutually elaborated process. Through the lens of imagining, we see that Gunnar and Janne use their hands to imaginatively depict multiple aspects with this gestural representation. The representation mediates their collective exploration of several different possibilities (Nemirovsky \& Ferrara, 2009). Janne's introduction of a new strategy of reversing the task appears towards the end of the sequence. This proposed thought experiment also constitutes an metaimaginative production by altering the given situation with an alternative form of imagining in an attempt to shed light on the initial task (Steier \& Kersting, in press). Though this suggestion is not taken immediately up by Gunnar, the possibility of a three-dimensional globe will again become relevant in the next sequence.

\section{Introducing a Digital earth as a resource to understand the complexity of maps}

As the episode continues, Gunnar and Janne discuss the importance of dimensionality but are still not able to confirm their answer of the shortest path with a suitable representation. We omit several of these turns from the transcript as no new representations are introduced and start the next excerpt at turn 54. In this third sequence, we see the group introduce a new digital representation from outside the module in the form of GoogleEarth ${ }^{\mathrm{TM}}$. By taking turns manipulating the perspective and inscribing imagined pathways on the the screen, as displayed in Excerpt 3, the group ultimately reaches a satisfactory resolution.

Excerpt 3

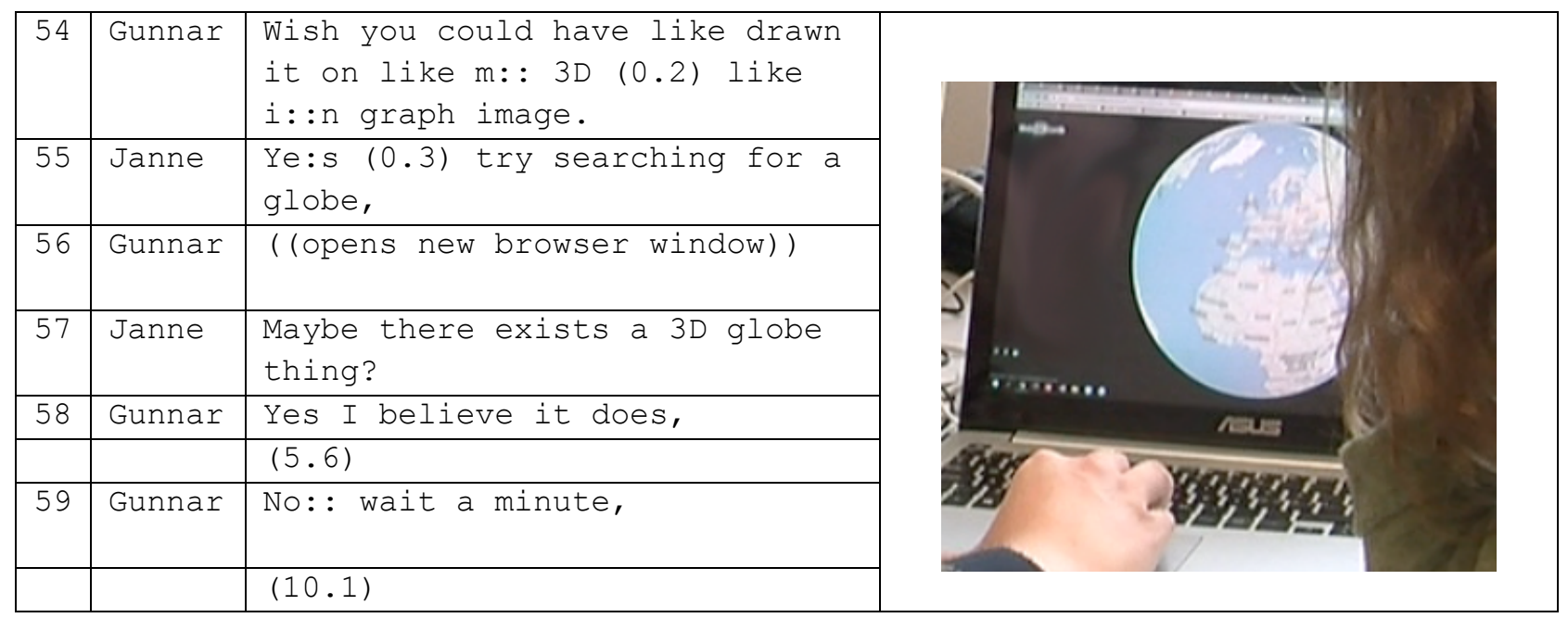




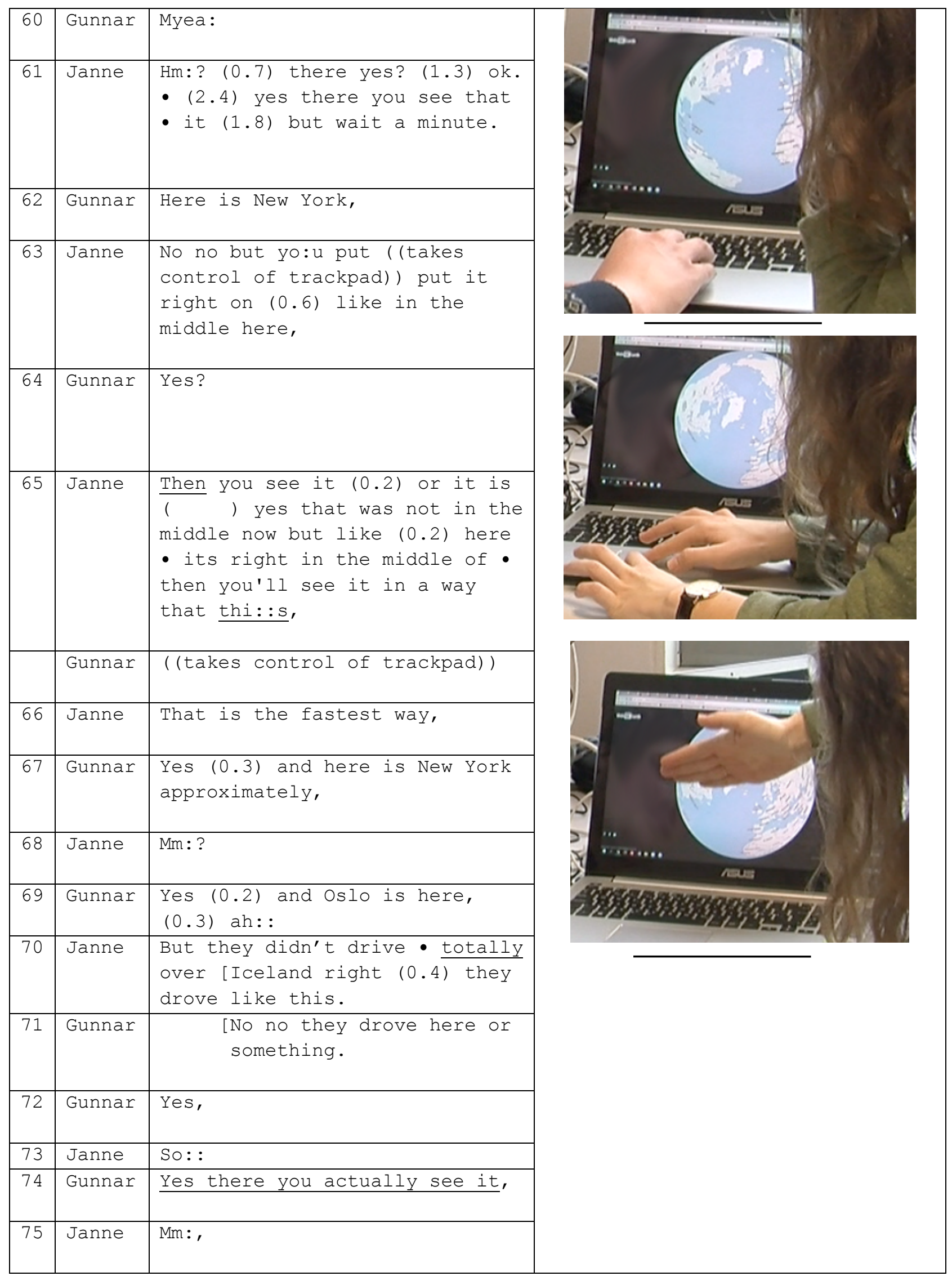




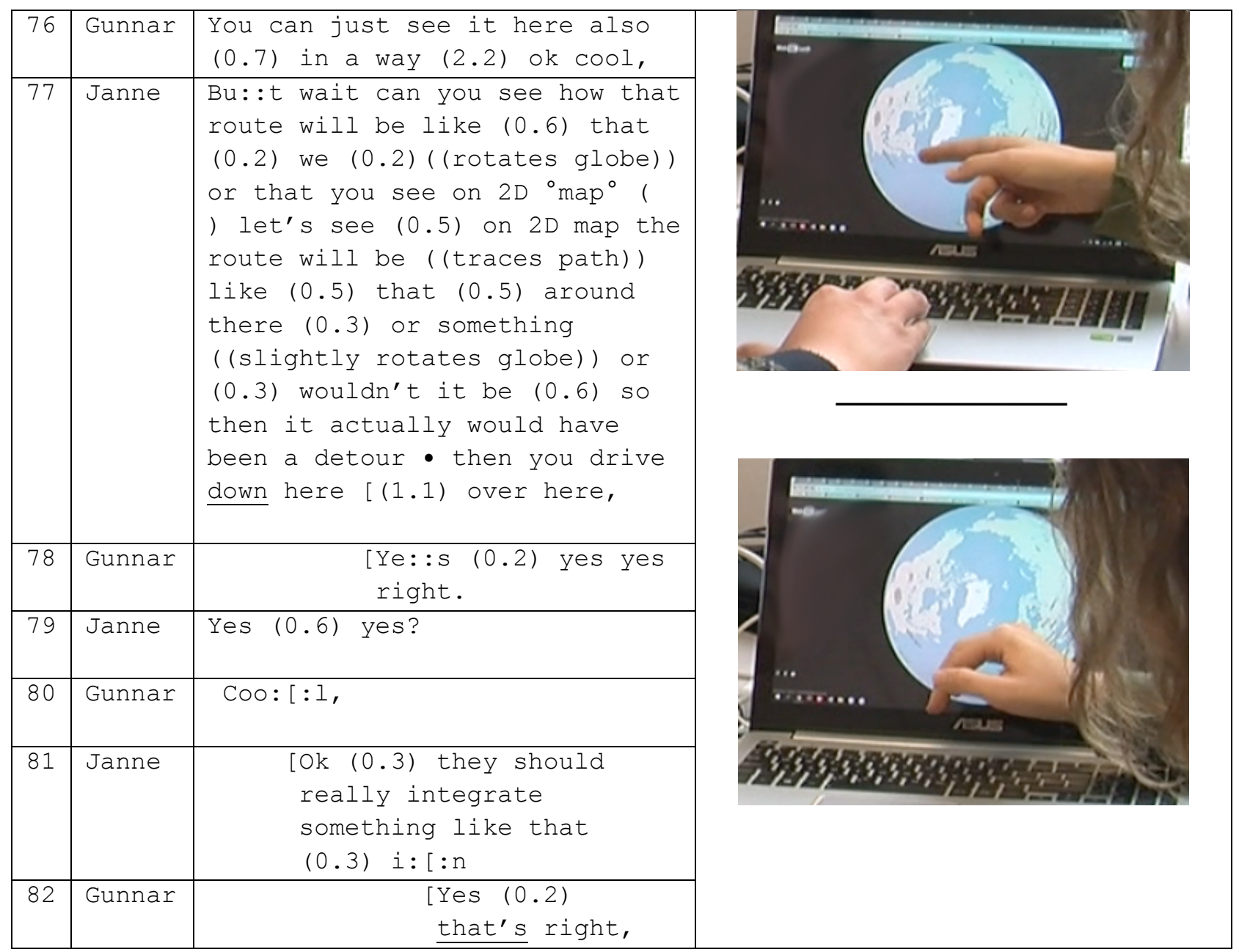

The final sequence begins when Gunnar mentions that he might have preferred a threedimensional "graph" image in the module. This prompts Janne to return to her earlier suggestion of using a globe. This time, she suggests searching the web (turns 55, 57) and Gunnar opens up a new tab. Gunnar is controlling the track pad on the laptop and opens up GoogleEarth ${ }^{\mathrm{TM}}$ (turns 58-60) and Janne exclaims "there yes" in recognition. This introduction of a new improvised representation results from the group recognizing that representational possibilities not currently available, namely "graph" features, might be useful in their discussion. This suggestion prompts them to reconfigure their local representational environment.

First, Gunnar rotates the view so that it is oriented over the Atlantic Ocean with a similar perspective to the original two-dimensional map. Gunnar starts to identify the cities (turn 62), but Janne reaches in to take control of the trackpad. She orients the view directly over the North Pole (turn 63-65). From this perspective, Janne reaches with her extended right hand over the screen 
demonstrating a straight path between the two cities. She again confirms "Then you'll see it in a way. It's the fastest way" (turn 65-66). The particular orientation of the globe, combined with the path marked by Janne's extended hand, both serve to mediate the group in imagining and confirming this pathway as the fastest.

At this point, Gunnar takes back control of the trackpad and marks the two cities using the cursor on the screen and the path between them (turn 67-69). Marking the imagined location of these cities, though not labeled on the globe, links this new representation to the work performed with their previous representations. Then, using her right index finger, Janne repeats this path while noting that the path does not actually pass over Iceland but only approaches it which Gunnar also agrees with (turn 70-72). These turns demonstrate a level of precision not available to the pair with their previous gestural depictions.

Gunnar begins to rotate the image again saying "cool" in an apparent attempt to close the task. However, Janne again takes control of the trackpad and returns to her earlier thought experiment about reversing the question (turn 77). She rotates the view back to the original perspective that lines up with the map in the module. She confirms that a straight path on the two-dimensional map would take a "detour" well below Iceland in a path that would not be the fastest. They express agreement that they have resolved the task (turn 78-80). Finally, Janne suggests that the web-module would be improved with the inclusion of a three-dimensional globe instead of or in addition to the static map. With this metareflection on the representational possibilities of the module, they move on to the next section of the module.

In this sequence, Janne and Gunnar have reached a satisfactory conclusion to their task and are able to advance to the next section of the module. The introduction of GoogleEarth ${ }^{\mathrm{TM}}$ as an improvised representation becomes essential for them in confirming the flight route as the shortest path. Though Janne had suggested using a globe earlier, Gunnar's mention of a threedimensional graph allowed her to repeat this suggestion. In a process similar to their appropriation of the depictive gesture in the earlier sequences, they collaboratively manipulate the representation by taking turns controlling the trackpad to rotate the globe and by gesturing over the top of the image. Imagining, in this sequence, involves the collective manipulation of the digital earth and the inscription of possible pathways over top that are collectively performed and collectively perceivable. These actions are not separate from the activity, but constitute imagining in action (Nishizaka, 2003). 
GoogleEarth ${ }^{\mathrm{TM}}$ has a few representational affordances that differ from their previous gestural depictions. It allows the pair to rotate the image while preserving the dimensional relationships (the "graph" lines of latitude and longitude). In addition to rotation and dimensional affordances, GoogleEarth ${ }^{\mathrm{TM}}$ also can be thought of as a three-dimensional representation presented as a two-dimensional digital image. That is, the flatness of the screen allowed Janne to easily inscribe a two-dimensional straight line with her extended hand. These particular manipulations made it possible for Gunnar and Janne to crosswalk between the two-dimensional and three-dimensional perspectives. It is also important to note that these affordances of GoogleEarth ${ }^{\mathrm{TM}}$ allowed Janne to return to her earlier thought experiment by confirming that the inverse of the given task is not the shortest route. Thus, this thought experiment, as an imaginative strategy, supports the conclusion that the curved path is in fact the fastest route.

\section{DISCUSSION}

Our analytical work has been guided by the research question asking how small groups of students collaboratively improvise, introduce, and make meaning with representations that extend across multiple modalities. We now summarize the above findings and discuss them in relation to prior research on and approaches to student-generated representations in meaningmaking processes.

One important aspect of the analysis involved attention to gesture as a form of improvised representation. The use of gestural depictions was a fairly common response among other observed groups engaging with the task of finding the shortest path on a map. Of the 15 groups, we observed nine groups engage in some form of gestural depiction. This observation suggests that certain disciplinary tasks may prompt the use of improvised representations; bodily depictions are often the most immediately available resource. Additionally, introducing new material representations of the earth beyond the gestural such as basketballs, a sandwich, and drawings, was another feature of several observed groups. One group with a similar initial premise as Janne and Gunnar, namely imagining their fist to be the earth, inscribed flight paths by literally drawing on the hand with a pen to view how this path might become distorted. We organize the rest of the discussion around three areas: imagination in CSCL settings, shifts between representations and across modalities, and maps as disciplinary representations. We 
present these areas in relation to the group of Janne and Gunnar and our analysis of their meaning-making process.

\section{Imagining with representations in CSCL settings}

The task of finding the shortest path between Oslo and New York and the associated digital map were quickly understood to be insufficient representational resources for Gunnar and Janne to elaborate and justify their initial response. Accordingly, the students improvised several important representations while working with this task. These representations included gestural depiction and a digital globe. The task itself required imagining the curved line on the map to be the shortest path on a round earth. To mediate this imagining, the first improvised representation was as a gestural depiction of a round earth along with a dynamic relationship to a flat map and possible airplane flight paths over these flat and curved surfaces.

Although the use of hands as representations came early in the episode, the gestural depictions gradually grew more sophisticated as layers of meaning were added. We saw how a gestural model grew out of attempts to depict a curved surface and quickly became a shared resource that was used and appropriated by both of the participants. Over several turns of interaction, the gesture became more sophisticated as Gunnar and Janne modified it, adding features, inscribing these features with meaning, and passing it back and forth. The location of the cities, strategies for alternating between two and three dimensions, and alternate flight paths, all became features of the representation as their collaboration progressed. The process through which this group developed and negotiated a representational tool with more features and complexity echoes the study by Enyedy (2005) in which younger students invented map conventions in socially coordinated activity.

Sociocultural approaches to imagining are important for making sense of how this improvised representation came to be (Murphy, 2004; Zittoun \& Gillespie, 2015). Gunnar and Janne were attempting to imagine conditions in which a curved line would in fact be straight. In accordance with this view of imagining as materially distributed (Hutchins, 2010; Nemirovsky \& Ferrara, 2009), we understand that the emerging gestural depiction was a mediational means to explore this task. The emergence of the gestures as a resource for imagining for both Janne and Gunnar underlines the social aspects of imagining. Imagining was required for the participants to see their hands as the referents, as the earth, or as a flat map. They took turns adding features to the gestures in turn supporting their collaborative imagining. Additionally, further layers of 
meaning, such as the location of Oslo or New York were briefly indicated indexically, but then were preserved as imaginative features of the constructed representation. That is, there were no visual marks indicating these cities, but the initial proposals were enough for the group to refer to them in subsequent manipulations of the gesture. In a classic series of studies by Ochs and colleagues (Ochs, Jacoby, \& Gonzales, 1994; Ochs, Gonzales, \& Jacoby, 1996), professional scientists were shown to engage in imaginative processes (interpretive journeys) by becoming the physical phenomena and inhabiting the scientific representations. Similarly, Gunnar and Janne, by tracing possible flight paths were both entertaining possibilities for action (Nemirovsky \& Ferrara, 2009) as well as imaginatively performing these journeys (Ochs et al., 1994).

The second mode of improvised representation involved the use of GoogleEarth ${ }^{\mathrm{TM}}$. This representation emerged based on the representational needs of the task and came in response to the need for a three-dimensional depiction of the of the earth and eventually to Janne's thought experiment of reversing the task. It is important to consider the conditions in which the need for this improvised representation were identified. First, Janne proposed a reversal of the given task as a kind of thought experiment. This proposal prompted her to identify a globe as a potentially productive resource. She did not seem to see one available in the room, and Gunnar did not fully take up the suggestion. However, a few turns later, Gunnar proposes that a "3D graph" might be helpful in shifting between two and three dimensions. Under these conditions, they turn to a web search. In any case, GoogleEarth ${ }^{\mathrm{TM}}$, as a representation, did not immediately resolve the challenge for the students. Similar to their earlier gestural depiction, the pair took turns rotating the model, and adding imaginary flight paths and lines over the surface of the image. We have thus seen how both a gestural depiction and GoogleEarth ${ }^{\mathrm{TM}}$ were improvised and introduced, as well as how the pair made meaning through the development of these representations.

\section{Managing shifts between representations and across modalities}

An additional important aspect of the development of improvised representations involves the ways that students worked together to manage shifts between representations and across modalities. Our findings suggest that shifts across boundaries of modalities might be a fundamental feature of activities that foster the emergence of improvised representations in collaborative meaning-making processes. The task invited students to navigate a representational 
landscape that allowed them to alternate between three distinct sets of modalities: digital/physical, verbal/gestural, and representations of two or three dimensions.

The three excerpts we presented in this study characterize three different stages in the meaning-making process of a group of students. In each stage, the patterns of shifts among modalities are different and help to shed light on how new representations are improvised and introduced. In Excerpt 1, the students shifted quickly between the digital and space of the learning environment and the physical space of the classroom as they tried to frame the representational challenge of finding the shortest path on a world map. Their conversation was characterized by a quick succession of moves between pointing to and tracing lines on the screen and developing a gestural vocabulary to represent shifts between two and three dimensions. It seems that their frequent shifts helped them to identify key issues of the task at hand.

In Excerpt 2, the students had established an initial understanding of representational challenges and had probed different ways of approaching the task. They continued to explore the workings of maps in relation to the task. Doing so, they struggled to become increasingly fluent in shifting among multimodal constellations of representations. The shifts between digital and physical, verbal and gestural, and two- and three-dimensional representations seemed to have helped them deepen their understanding of what was needed to solve the task.

In the last excerpt, the students had gained enough familiarity with navigating the representational space to introduce GoogleEarth ${ }^{\mathrm{TM}}$ as yet another representation (the representation that would allow them to solve the task satisfactorily), and were able to orchestrate the interplay of different modalities successfully. The pair was fluent in their collaborative exploration of the digital representation, taking turns in rotating and zooming in and out of the map while tracing lines and flight routes on top of the screen. The shifts between modalities were deliberate and occurred less frequent than the swift and possibly erratic shifts we observed in the first episode.

These shifts may also be conceptualized through the notion of joint attention, an important theme in CSCL literature. Joint attention has been examined through several different lenses and approaches, including the notion of group practices (Stahl, 2017) to account for the ways that participants make their work visible to each other; through eye-tracking methods (Schneider et al., 2018) to record literal shifts in visual attention; and through attention to bodily orientation and gaze around shared digital surfaces (Evans et al., 2011). In this study, the 
participants' joint attention across these modalities facilitated the development from individual gestural productions to a shared gestural practice, and ultimately to the collaborative use of the digital map.

To summarize, our findings indicate that in developing improvised representations students shift across different modalities as a way to make meaning of and eventually master a task that presents them with representational challenges. Students engage in a variety of creative and imaginative strategies as they fluidly shift between bodily, material, and digital representations which thus become an important feature of imagining with improvised representations in CSCL environments.

\section{Maps as Disciplinary Representations}

In this study we have taken maps as a disciplinary domain to investigate the emergence and appropriation of improvised representations within collaborative meaning-making processes. While our findings extend current knowledge of how learners introduce and establish new representations by drawing on shared imaginative reasoning, the setting of (digital) maps allows us to contextualize our findings within a broader body of literature on representational challenges of maps.

In particular, our findings both corroborate and extend observations of Anderson and Leinhardt (2002) who studied expert and novice geographers' ability to use maps as representations of the surface of the earth. Our results are consistent with the observation that learners often try to directly manipulate maps, e.g. by curling maps physically, in order to "look through the map and connect it to the globe" (Anderson \& Leinhardt, 2002). The authors characterized these manipulations as a weak visualization strategy in that learners were not able to connect their image of the curved earth or globe back to the flat map representation. A robust strategy, on the other hand, was characterized by the great extent to which it allowed learners to establish such a connection. In other words, competent readers of maps were able to use maps as a tool for reasoning while novices reasoned with and within the map itself (Anderson \& Leinhardt, 2002). Moreover, Anderson and Leinhardt noted that learners who displayed weak visualization strategies would often draw on other resources (such as knowledge of flight routes) to assist them in solving their tasks. Our study extends these findings. Among the 15 observed groups we identified similar patterns of reasoning with and within the maps as well as the need 
to draw on new objects and gestures for representational assistance when finding the shortest path on a world map. However, instead of just identifying this issue, we focused on the imaginative processes of improvising and introducing new representations in. This detailed approach provides an insight into how learners might transition from everyday reasoning within the map itself to more sophisticated uses of maps as a tool for reasoning - a crucial distinction emphasized by Anderson and Leinhardt (2002).

Maps mediate a unique type of CSCL activity in that they reorganize space in ways that contradict our experience of the physical world (Taylor \& Hall, 2013). Accordingly, we emphasize the importance of imaginative reasoning when collaborating and communicating with digital and physical maps. Students must transcend their experience of perceptible space to interact with spaces that are different from the present situation. Above all, this is the case when the spatial and temporal scales of the maps are too large to be compared with the everyday experiences of students (Eriksson et al., 2014), as is the case with intercontinental flights on a global scale. Even though maps are a ubiquitous feature of everyday life, reading and navigating maps requires imagining that is often overlooked in cartographic instruction. Understanding how maps represent curved spaces requires instruction that allows students to fluently navigate representational shifts across modalities of medium and dimension.

\section{CONCLUDING REMARKS}

Based on studies of collaborative learning with multiple representations, we know that students employ creativity as they navigate and shift between material and digital representations (White \& Pea, 2011), and as they reconfigure representations to understand a problem (Enyedy, 2005). Interactional approaches to students' use of representations in CSCL environments have articulated the processes through which these representations develop meanings (Çakir et al., 2009; Dwyer \& Suthers, 2006; Furberg, Kluge, \& Ludvigsen, 2013). However, even in welldesigned CSCL environments, students may have difficulty expressing particular ideas within the given representational constraints. In such situations, students may look for new opportunities to make their understandings relevant and perceivable to collaborators. In this study, we have identified improvised representations as an important feature of many problemsolving situations that are located in the real world. Attention to where such representations come from extends the CSCL field by highlighting the fact that collaborative learning may occur 
with representations outside of the designed environment or task. More specifically, our study has showed in detail how students within CSCL settings improvise new representations in order to solve a problem, and how this is enacted as a collaborative achievement, involving both verbal, bodily and digital resources. In a recent squib in this journal, Stahl (2017) argues that attending to group practices gives insight into the kind of pervasive, yet often invisible, work of novice learners. We suggest that improvised representations are one such form of locally enacted group practice that has remained invisible precisely because they emerge from outside the designed environment. We saw that the particular task in this study seemed to prompt such improvised representations and we hope that future research can help us better understand the qualities and features of such tasks. Our findings demonstrate that improvised representations develop collectively, as mutually elaborated forms which develop meaning as they are passed back and forth among participants. Importantly, these forms shift across modalities in response to the representational affordances of the given modality. Gestural depictions support quickly expressed relationships but may lack the precision of a digital simulation of a globe.

Additionally, this study extends CSCL research by proposing a sociocultural approach to imagining as a means to understand several different aspects of collaboration with representations. This approach emphasizes that students' imagination of new representational possibilities for solving problems is a collaborative enterprise, not restricted to the realm of individual cognition or mental images,. We identified how imaginative processes were required for participants to recognize that altering their local representational environment might be productive. Additionally, imagination was essential to perceiving new representations as their referents in interaction. By approaching imagining as a means to "extend the horizon of possibilities that students come to entertain" (Nemirovsky \& Ferrara, 2009, p. 173), we documented how students employed sophisticated imaginative practices to consider, compare, and test out ways of expressing possible flight paths and the corresponding changes in dimensionality. Treating the given task as an imaginative challenge also accounts for the way students in this study moved beyond their initial verbal response to a manipulation of the local environment. Imagining as a collaborative learning process involves both considering situations that are different from the perceivable present and seeing new possibilities in the present. More broadly, we argue that imagination, along with improvised representations, are productive 
analytic concepts for expanding our understanding of where and how meaning-making unfolds in CSCL environments.

\section{Transcription Conventions}

Sign Explanation

(2.5) Time interval between speech in tenths of a second

$<>\quad$ Right and left carats indicate that the talk between the participants speeded up or slowed down

word Underlining indicates emphasis on words and expressions

[ Brackets indicate where overlapping talk starts

$::$ Colons indicate the lengthening of a word or sound

., ? Punctuation markers indicates intonation. The period indicates falling intonation. The comma and question-mark indicate rising intonation

( ) Empty parentheses indicate that it was difficult to hear what was said

${ }^{\circ}$ word ${ }^{\circ} \quad$ Indicates that the word or sound is softer compared to the surrounding talk

((looks up)) A sentence that appears within double parentheses describes an action

- Dot marks where the corresponding gesture figure occurs in the transcript

\section{ACKNOWLEDGEMENTS}

This work was supported by the Research Council of Norway (ProjectNo. 246723) and the Olav Thon Foundation. We wish to thank the many people involved in the development of the learning resources presented in this project, especially our ReleQuant colleagues.

\section{REFERENCES}

Anderson, K. C., \& Leinhardt, G. (2002). Maps as Representations: Expert Novice Comparison of Projection Understanding. Cognition and Instruction, 20(3), 283-321. http://doi.org/10.1207/S1532690XCI2003

Barab, S. A., Hay, K. E., Barnett, M., \& Keating, T. (2000). Virtual solar system project: Building understanding through model building. Journal of Research in Science Teaching, 37(7), 719-756.

Battersby, S. E., \& Kessler, F. C. (2012). Cues for Interpreting Distortion in Map Projections. 
Journal of Geography, 111(3), 93-101. http://doi.org/10.1080/00221341.2011.609895

Bausmith, J. M., \& Leinhardt, G. (1998). Middle-school students' map construction:

Understanding complex spatial displays. Journal of Geography, 97(3), 93-107. http://doi.org/10.1080/00221349808978834

Bednarz, S. W., Acheson, G., \& Bednarz, R. S. (2006). Maps and Map Learning in Social Studies. Social Education, 70(7), 398-404. http://doi.org/10.4324/9780203841273

Brainerd, J., \& Pang, A. (2001). Interactive map projections and distortion. Computers \& Geosciences, 27(3), 299-314. http://doi.org/Doi 10.1016/S0098-3004(00)00108-4

Bungum, B., Henriksen, E. K., Angell, C., Tellefsen, C. W., \& Bøe, M. V. (2015). ReleQuant Improving teaching and learning in quantum physics through educational design research. Nordina: Nordic Studies in Science Education, 11(2), 153-168.

ÇakIr, M. P., Zemel, A., \& Stahl, G. (2009). The joint organization of interaction within a multimodal CSCL medium. International Journal of Computer-Supported Collaborative Learning, 4(2), 115-149. http://doi.org/10.1007/s11412-009-9061-0

Davidsen, J., \& Ryberg, T. (2017). "This is the size of one meter": Children's bodily-material collaboration. International Journal of Computer-Supported Collaborative Learning, 12(1), 65-90. http://doi.org/10.1007/s11412-017-9248-8

Derry, S. J., Pea, R. D., Barron, B., Engle, R. A., Erickson, F., Goldman, R., ... Sherin, B. L. (2010). Conducting Video Research in the Learning Sciences: Guidance on Selection, Analysis, Technology, and Ethics. Journal of the Learning Sciences, 19(1), 3-53.

Downs, R. M., \& Liben, L. S. (1991). The development of expertise in geography: A cognitivedevelopmental approach to geographic education. Annals of the Association of American Geographers, 81, 304-327.

Duranti, A., \& Goodwin, C. (1992). Rethinking context: language as an interactive phenomenon. Cambridge: Cambridge University Press.

Dwyer, N., \& Suthers, D. D. (2006). Consistent practices in artifact-mediated collaboration. International Journal of Computer-Supported Collaborative Learning, 1(4), 481-511. http://doi.org/10.1007/s11412-006-9001-1

Enyedy, N. (2005). Inventing mapping: Creating cultural forms to solve collective problems. Cognition and Instruction, 23(4), 427-466.

Eriksson, U. (2014). Reading the Sky (PhD thesis). Uppsala University.

Eriksson, U., Linder, C., Airey, J., \& Redfors, A. (2014). Who Needs 3D When the Universe Is Flat? Science Education, 98(3), 412-442. http://doi.org/10.1002/sce.21109

Evans, M. A., Feenstra, E., Ryon, E., \& McNeill, D. (2011). A multimodal approach to coding discourse: Collaboration, distributed cognition, and geometric reasoning. International Journal of Computer-Supported Collaborative Learning, 6(2), 253-278. http://doi.org/10.1007/s11412-011-9113-0

Farmann, J. (2010). Mapping the digital empire: Google Earth and the process of postmodern cartography. New Media and Society, 12(6), 869-888.

Furberg, A. (2016). Teacher support in computer-supported lab work: bridging the gap between lab experiments and students' conceptual understanding. International Journal of Computer-Supported Collaborative Learning, 11(1), 89-113. http://doi.org/10.1007/s11412-016-9229-3

Furberg, A., Kluge, A., \& Ludvigsen, S. (2013). Student sensemaking with science diagrams in a computer-based setting. International Journal of Computer-Supported Collaborative Learning, 8(1), 41-64. http://doi.org/10.1007/s11412-013-9165-4 
Gee, J. P., \& Green, J. L. (1998). Discourse Analysis, Learning, and Social Practice : A Methodological Study. Review of Research in Education, 23, 119-169.

Greeno, J. G. (1997). On Claims That Answer the Wrong Questions. Educational Researcher, 26(1), 5-17. http://doi.org/10.3102/0013189X026001005

Greeno, J. G., \& Hall, R. P. (1997). Practicing Representation: Learning with and about representational forms. Phi Delta Kappan, 78(5), 361-367.

Henriksen, E. K., \& Angell, C. (2010). The role of 'talking physics' in an undergraduate physics class using an electronic audience response system. Physics Education, 45(3), 278-284.

Henriksen, E. K., Bungum, B., Angell, C., Tellefsen, C. W., Frågåt, T., \& Vetleseter Bøe, M. (2014). Relativity, quantum physics and philosophy in the upper secondary curriculum: challenges, opportunities and proposed approaches. Physics Education, 49(6), 678-684.

Hutchins, E. (2010). Enaction, imagination, and insight. In J. Stewart, O. Gapenne, \& E. A. Di Paolo (Eds.), Enaction: Towards a New Paradigm for Cognitive Science (pp. 425-450). Cambridge, MA: MIT Press.

Jefferson, G. (2004). Glossary of Transcript Symbols with an Introduction. Conversation Analysis: Studies from the First Generation. http://doi.org/10.1075/pbns.125.02jef

Jordan, B., \& Henderson, A. (1995). Interaction Analysis: foundation and practice. The Journal of the Learning Sciences. http://doi.org/10.1207/s15327809j1s0401_2

Jornet, A., \& Steier, R. (2015). The Matter of Space: Bodily Performances and the Emergence of Boundary Objects During Multidisciplinary Design Meetings. Mind, Culture, and Activity, 22(2), 129-151.

Kersting, M., \& Steier, R. (2018). Understanding curved spacetime - the role of the rubber sheet analogy in learning general relativity. Science \& Education, 27(7), 593-623. http://doi.org/10.1007/s11191-018-9997-4

Krange, I., \& Ludvigsen, S. (2008). What does it mean? Students' procedural and conceptual problem solving in a CSCL environment designed within the field of science education. International Journal of Computer-Supported Collaborative Learning, 3(1), 25-51. http://doi.org/10.1007/s11412-007-9030-4

Lakoff, G., \& Johnson, M. (1999). Philosophy in the Flesh: The Embodied Mind and Its Challenge to Western Thought. Basic Books. http://doi.org/10.1590/S010244502001000100008

Latour, B. (1986). Visualisation and cognition: Drawing things together. Knowledge and Society: Studies in the Sociology of Culture Past and Present, 6, 1-40. http://doi.org/10.1002/9780470979587.ch9

Lemke, J. L. (1990). Talking science: Language, learning, and values. Norwood, New Jersey: Ablex Publishing Corporation.

Linell, P. (2009). Rethinking language, mind, and world dialogically: Interactional and contextual theories of human sense-making. IAP.

Ludvigsen, S. (2012). Commentary. Instructional Science, 40(5), 849-855. http://doi.org/10.1007/s11251-012-9233-6

McNeill, D. (1992). Hand and mind: What gestures reveal about thought. Chicago: University of Chicago Press.

Medina, R., \& Suthers, D. D. (2013). Juxtaposing practice: Uptake as modal transposition. In Proc. 10th International Conference on Computer Supported Collaborative Learning (CSCL '13), June 15-19, 2013 (pp. 328-335). Madison, WI.

Mercer, N. (2004). Sociocultural discourse analysis: analysing classroom talk as a social mode of 
thinking. Journal of Applied Linguistics, 1(2), 137-168.

http://doi.org/10.1558/japl.2004.1.2.137

Mercer, N. (2008). Changing our minds: a commentary on 'Conceptual change: a discussion of theoretical, methodological and practical challenges for science education'. Cultural Studies of Science Education, 3(2), 1-12. http://doi.org/10.1007/s11422-008-9099-8

Murphy, K. M. (2004). Imagination as joint activity: The case of architectural interaction. Mind, Culture, and Activity, 11(4), 267-278.

Nemirovsky, R., \& Ferrara, F. (2009). Mathematical imagination and embodied cognition. Educational Studies in Mathematics, 70(2), 159-174.

Nemirovsky, R., Rasmussen, C., Sweeney, G., \& Wawro, M. (2012). When the classroom floor becomes the complex plane: Addition and multiplication as ways of bodily navigation.

Journal of the Learning Sciences, 21(2), 287-323. http://doi.org/10.1080/10508406.2011.611445

Nishizaka, A. (2003). Imagination in action. Theory \& Psychology, 13(2), 177-207.

Nordby, M., Knain, E., \& Jonsdottir, G. (2017). Vocational students ' meaning-making in school science - negotiating authenticity through multimodal mobile learning. NorDiNa, 13(1), $52-65$.

Ochs, E., Gonzales, P., \& Jacoby, S. (1996). 'When I come down I'm in the domain state': grammar and graphic representation in the interpretive activity of physicists. In E. Ochs, E. Schegloff, \& S. Thompson (Eds.), Interaction and Grammar. Cambridge: Cambridge University Press.

Ochs, E., Jacoby, G., \& Gonzales, P. (1994). Interpretive Journeys: How Physicists Talk and Travel Through Space. Configurations, (1), 151-171.

Prain, V., \& Tytler, R. (2012). Learning Through Constructing Representations in Science: A framework of representational construction affordances. International Journal of Science Education, 34(17), 2751-2773. http://doi.org/10.1080/09500693.2011.626462

Prain, V., \& Waldrip, B. (2006). An exploratory study of teachers' and students' use of multimodal representations of concepts in primary science. International Journal of Science Education, 28, 1843-1866.

Schneider, B., Sharma, K., Cuendet, S., Zufferey, G., Dillenbourg, P., \& Pea, R. (2018). Leveraging mobile eye-trackers to capture joint visual attention in co-located collaborative learning groups. International Journal of Computer-Supported Collaborative Learning, 13(3), 241-261.

Silseth, K. (2012). The multivoicedness of game play: Exploring the unfolding of a student's learning trajectory in a gaming context at school. International Journal of ComputerSupported Collaborative Learning, 7(1), 63-84. http://doi.org/10.1007/s11412-011-9132-x

Silseth, K. (2018). Students' everyday knowledge and experiences as resources in educational dialogues. Instructional Science, 46(2), 291-313. http://doi.org/10.1007/s11251-017-9429-X

Silvis et al. (2018). Community Technology Mapping : Insc ribing Places When "Everything I s on the Move" (Manuscript). International Journal of Computer-Supported Collaborative Learning.

Snyder, J. P. (1993). Flattening the Earth - Two Thousand Years of Map Projections. Chicago: The University of Chicago Press.

Stahl, G. (2017). Group practices: A new way of viewing CSCL. International Journal of Computer-Supported Collaborative Learning, 12(1), 113-126.

Steier, R., \& Kersting, M. (in press). Metaimagining and embodied conceptions of spacetime. 
Cognition and Instruction.

Steier, R., Pierroux, P., \& Krange, I. (2015). Embodied interpretation: Gesture, social interaction, and meaning making in a national art museum. Learning, Culture and Social Interaction, 7 , 28-42. http://doi.org/10.1016/j.lcsi.2015.05.002

Streeck, J. (2009). Gesturecraft. America. Amsterdam: John Benjamins Publishing Co.

Streeck, J., Goodwin, C., \& LeBaron, C. (2011). Embodied interaction in the material world: An introduction. In J. Streeck, C. Goodwin, \& C. LeBaron (Eds.), Embodied Interaction Language and Body in the Material World. Cambridge: Cambridge University Press.

Suthers, D. D. (2006). Technology affordances for intersubjective meaning-making. International Conference for Computers in Education, 1(2), 1-24.

Tang, K., Tan, S. C., \& Yeo, J. (2011). Students' Multimodal Construction of the Work-Energy Concept. International Journal of Science Education, 33(13), 1775-1804. http://doi.org/10.1080/09500693.2010.508899

Taylor, K. H., \& Hall, R. (2013). Counter-mapping the neighborhood on bicycles: Mobilizing youth to reimagine the city. Technology, Knowledge and Learning, 18(1-2), 65-93. http://doi.org/10.1007/s10758-013-9201-5

Tyner, J. A. (1987). Interactions of culture and cartography. The History Teacher, 20, 455-464.

Van Oers, B. (1998). From context to contextualizing. Learning and Instruction, 8(6), 473-488. http://doi.org/10.1016/S0959-4752(98)00031-0

Vygotsky, L. (1962). Thought and language. Cambridge: M.I.T. Press.

Vygotsky, L. (1978). Mind in Society: The Development of Higher Psychological Processes. Cambridge: Harvard University Press.

Wertsch, J. V. (1993). Voices of the Mind. Cambridge (MA): Harvard University Press.

White, T., \& Pea, R. (2011). Distributed by Design: On the Promises and Pitfalls of Collaborative Learning with Multiple Representations. Journal of the Learning Sciences, 20(3), 489-547. http://doi.org/10.1080/10508406.2010.542700

Wiegand, P. (1999). Children's Understanding of Maps. International Research in Geographical and Environmental Education, 8(1), 66-68. http://doi.org/10.1080/10382049908667591

Wood, D. (2010). Rethinking the Power of Maps. New York: The Guildford Press.

Zemel, A., \& Koschmann, T. (2013). Recalibrating reference within a dual-space interaction environment. International Journal of Computer-Supported Collaborative Learning, 8(1), 65-87. http://doi.org/10.1007/s11412-013-9164-5

Zittoun, T., \& Gillespie, A. (2015). Imagination in human and cultural development. London: Routledge. 